\title{
Electrochemical $\mathrm{CO}_{2}$ Reduction Reaction on 3d Transition Metal
}

\section{Single-Atom Catalysts Supported on Graphdiyne: a DFT Study}

Tianfu Liu, ${ }^{\text {ab }}$ Guoxiong Wang*a and Xinhe Bao ${ }^{\mathrm{a}}$

${ }^{a}$ State Key Laboratory of Catalysis, Dalian National Laboratory for Clean Energy, Dalian Institute of Chemical Physics, Chinese Academy of Sciences, Dalian, 116023, China

${ }^{\mathrm{b} C o l l e g e}$ of Energy, University of Chinese Academy of Sciences, Beijing, 100039, China

*Email: wanggx@dicp.ac.cn 
a

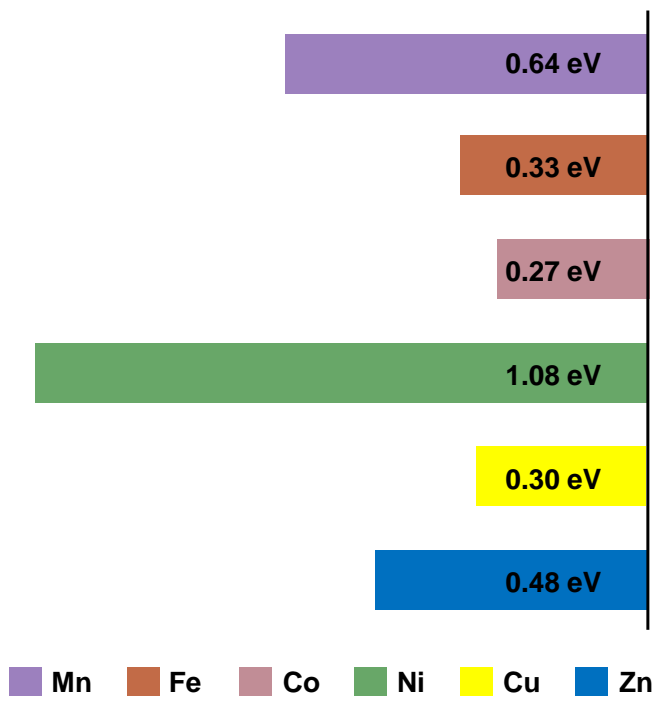

b

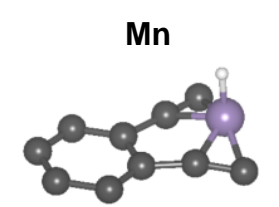

Co

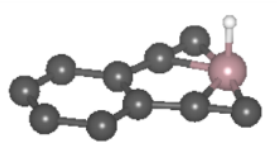

$\mathrm{Cu}$

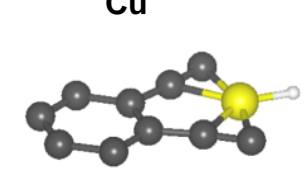

$\mathrm{Fe}$

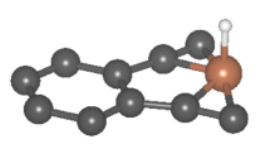

$\mathrm{Ni}$

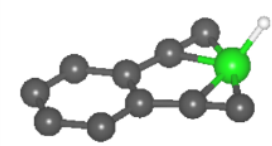

Zn

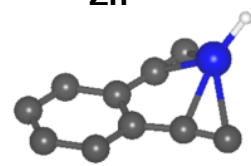

Figure S1. (a) The adsorption free energy of hydrogen on various SACs. (b) The related configurations of $* \mathrm{H}$ adsorption on $\mathrm{M}$-graphdiyne. Color code: gray for carbon, white for hydrogen, purple for $\mathrm{Mn}$, orange for $\mathrm{Fe}$, pink for $\mathrm{Co}$, green for $\mathrm{Ni}$, yellow for $\mathrm{Cu}$, blue for $\mathrm{Zn}$.

\section{Co}

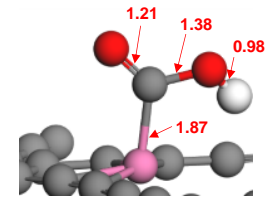

${ }^{*} \mathrm{COOH}$

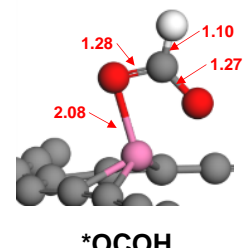

*OCOH

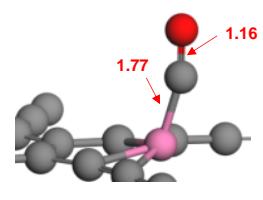

${ }^{*} \mathrm{CO}$

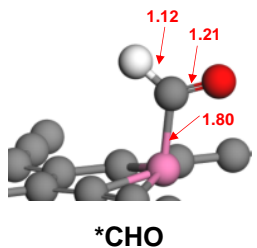

${ }^{*} \mathrm{CHO}$

Figure S2. The configurations of key intermediates $\left(* \mathrm{COOH},{ }^{*} \mathrm{OCOH},{ }^{*} \mathrm{CO}\right.$, and ${ }^{*} \mathrm{CHO}$ ) of $\mathrm{CO}_{2} \mathrm{RR}$ on Co-graphdiyne. Color codes: pink for $\mathrm{Co}$, gray for carbon, white for hydrogen, and red for oxygen. 
$\mathrm{Fe}$

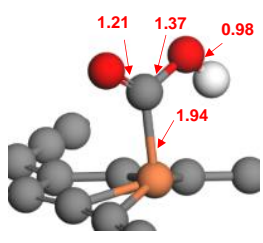

${ }^{*} \mathrm{COOH}$

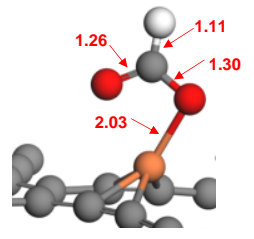

*OCOH

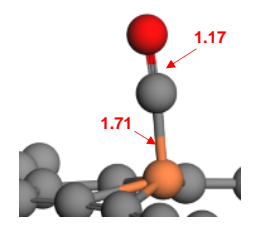

${ }^{*} \mathrm{CO}$

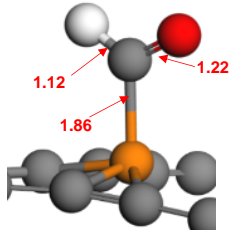

${ }^{*} \mathrm{CHO}$

Figure S3. The configurations of key intermediates $\left({ }^{*} \mathrm{COOH},{ }^{*} \mathrm{OCOH},{ }^{*} \mathrm{CO}\right.$, and $\left.{ }^{*} \mathrm{CHO}\right)$ of $\mathrm{CO}_{2} \mathrm{RR}$ on Fe-graphdiyne. Color codes: orange for $\mathrm{Fe}$, gray for carbon, white for hydrogen, and red for oxygen.

\section{Mn}
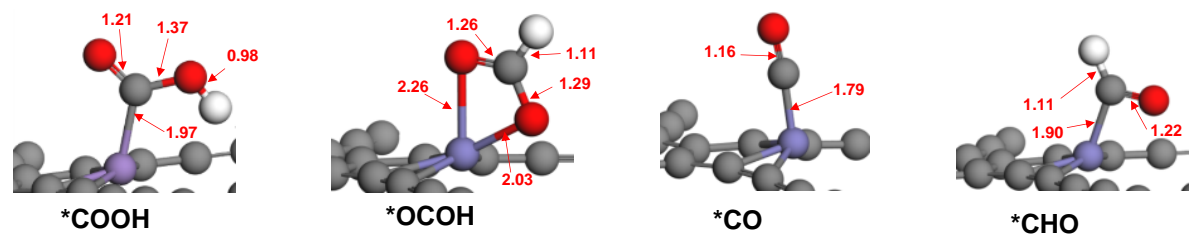

Figure S4. The configurations of key intermediates $\left({ }^{*} \mathrm{COOH},{ }^{*} \mathrm{OCOH},{ }^{*} \mathrm{CO}\right.$, and $\left.{ }^{*} \mathrm{CHO}\right)$ of $\mathrm{CO}_{2} \mathrm{RR}$ on Mn-graphdiyne. Color codes: purple for Mn, gray for carbon, white for hydrogen, and red for oxygen. 
a

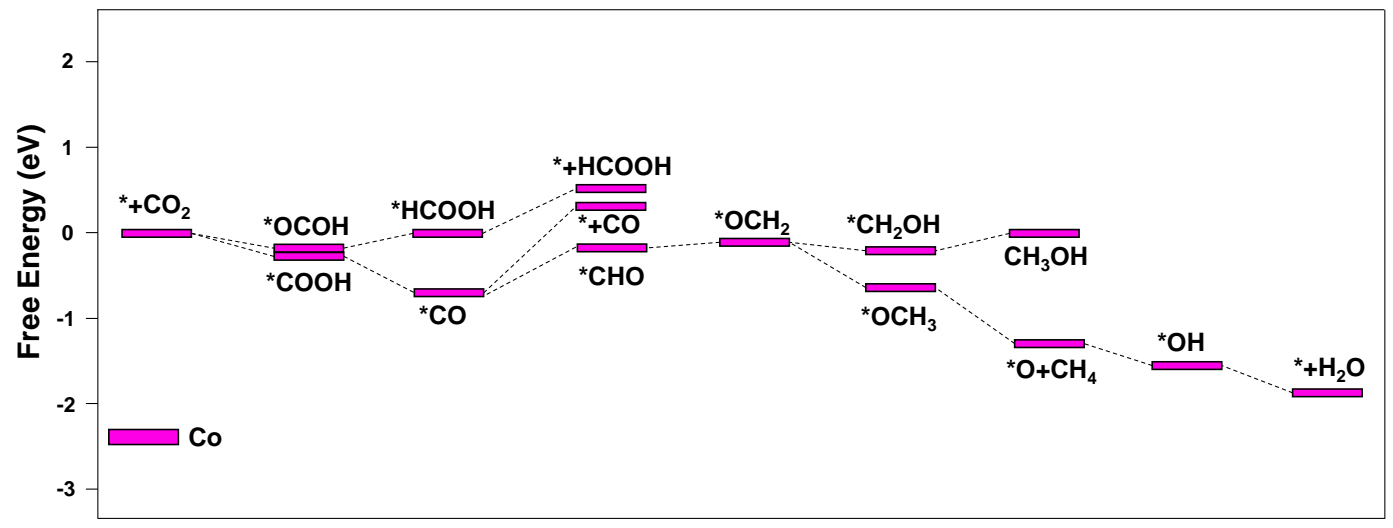

b

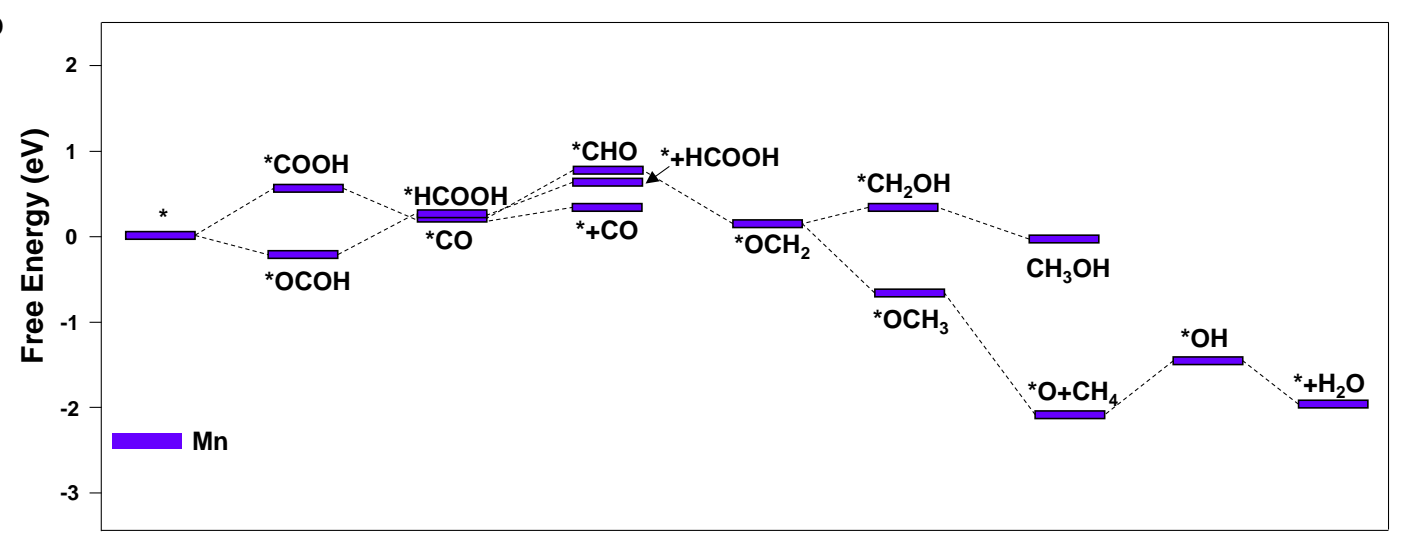

C

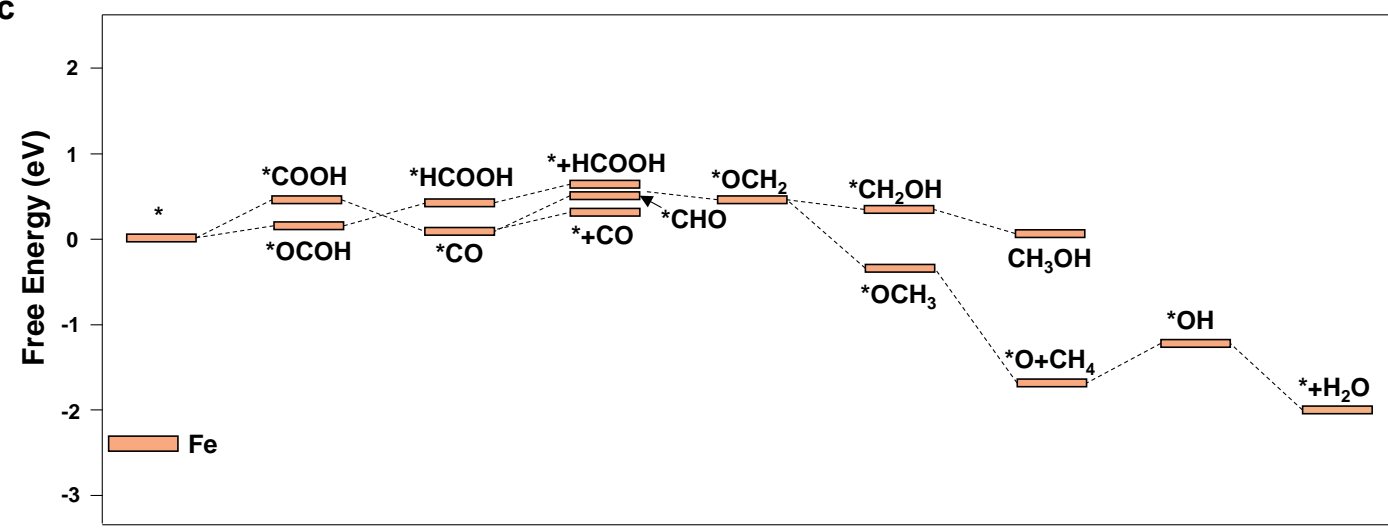

Figure S5. The free energy diagram of $\mathrm{CO}_{2} \mathrm{RR}$ on (a) Co-, (b) Mn-, (c) Fe-graphene. 


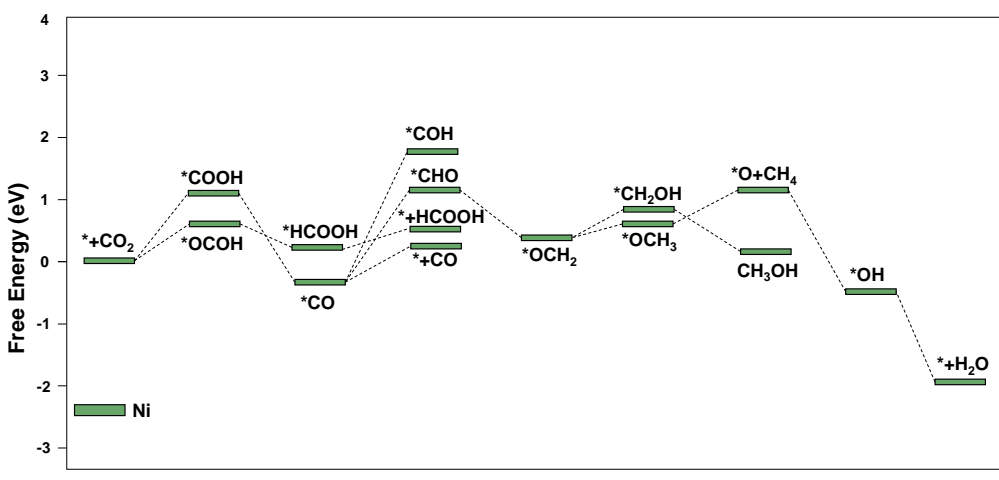

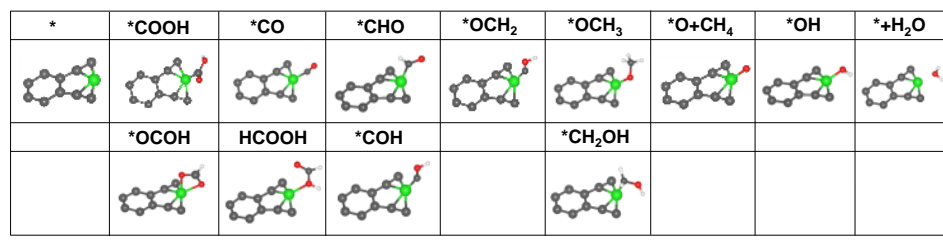

b

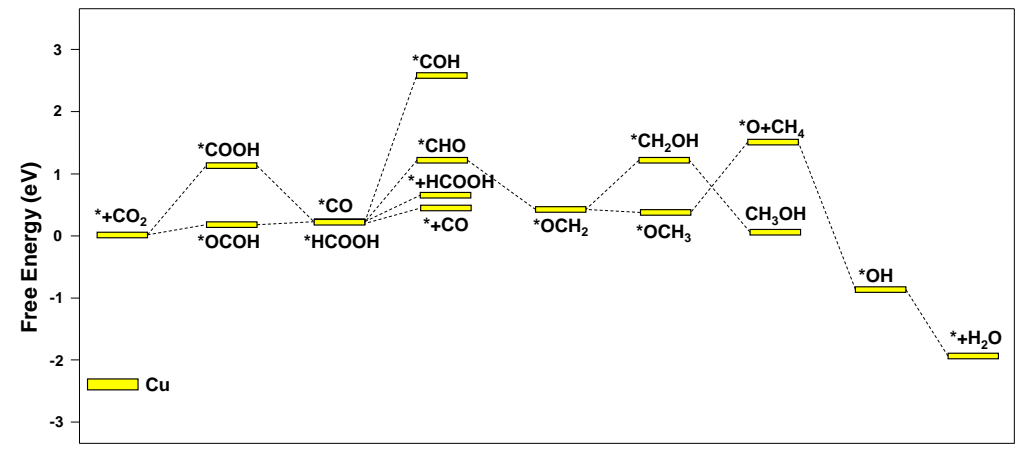

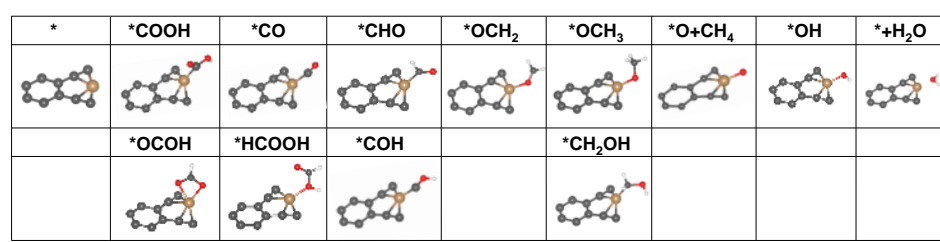

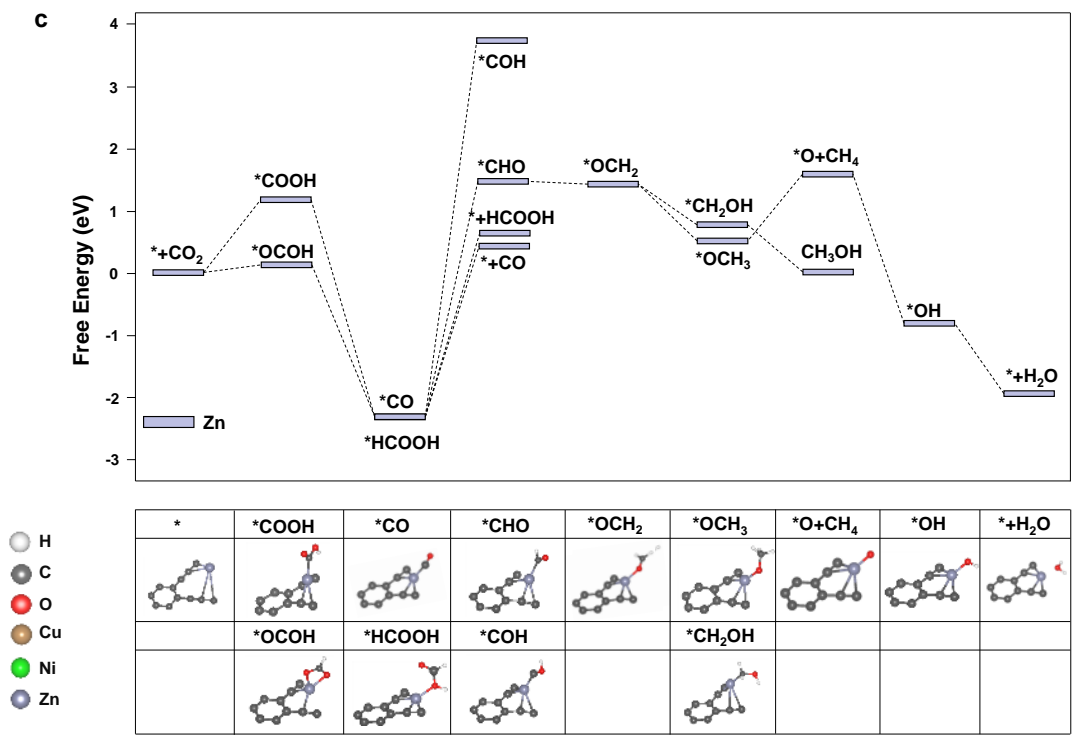

Figure S6. The free energy diagram of $\mathrm{CO}_{2} \mathrm{RR}$ on (a) $\mathrm{Ni}$-, (b) $\mathrm{Cu}-$, (c) Zn-graphdiyne, the related geometry configurations are shown below accordingly. 
Table S1. The calculated free energy corrections for adsorbates. All values are given in $\mathrm{eV}$

\begin{tabular}{cccc}
\hline Adsorbate & Zero Point Energy & $\int C_{p} d T$ & TS \\
\hline$* \mathrm{COOH}$ & 0.60 & 0.11 & 0.25 \\
$* \mathrm{OCOH}$ & 0.61 & 0.10 & 0.23 \\
$* \mathrm{CO}$ & 0.20 & 0.07 & 0.15 \\
$* \mathrm{HCOOH}$ & 0.81 & 0.07 & 0.13 \\
$* \mathrm{CHO}$ & 0.48 & 0.08 & 0.17 \\
$* \mathrm{COH}$ & 0.50 & 0.05 & 0.09 \\
$* \mathrm{CHOH}$ & 0.85 & 0.08 & 0.15 \\
$* \mathrm{OCH}$ & 0.77 & 0.10 & 0.20 \\
$* \mathrm{CH}_{2} \mathrm{OH}$ & 1.12 & 0.08 & 0.16 \\
$* \mathrm{OCH}$ & 1.08 & 0.11 & 0.27 \\
$* \mathrm{O}$ & 0.07 & 0.04 & 0.08 \\
$* \mathrm{OH}$ & 0.35 & 0.05 & 0.11 \\
\hline
\end{tabular}

Table S2. The adsorption energy of $\mathrm{CO}_{2}$ on metal-graphdiyne slabs

\begin{tabular}{cc}
\hline Metal-graphdiyne & $\begin{array}{c}\text { Adsorption energy on } \mathrm{CO}_{2} \\
(\mathrm{eV})\end{array}$ \\
\hline $\mathrm{Co}$ & -0.30 \\
$\mathrm{Cu}$ & -0.26 \\
$\mathrm{Fe}$ & -0.31 \\
$\mathrm{Mn}$ & -0.33 \\
$\mathrm{Ni}$ & -0.25 \\
$\mathrm{Zn}$ & -0.06 \\
\hline
\end{tabular}

Note: It could be seen that the $\mathrm{CO}_{2}$ adsorption energy on metal-graphdiyne is similar, from -0.25 to $-0.33 \mathrm{eV}$, except for Zn-graphdiyne. It is reported that the hydrogenation of $\mathrm{CO}_{2}$ to $* \mathrm{COOH}$ or $* \mathrm{OCOH}$ is the initial step with proton-coupled electron transfer in solution, which exhibits a much more stable adsorption. ${ }^{1,2}$ Therefore, the formation of $* \mathrm{COOH}$ and $* \mathrm{OCOH}$ on metal-graphdiyne was studied as the first step of $\mathrm{CO}_{2} \mathrm{RR}$ in the manuscript. 


\section{References:}

1. Back, S.; Lim, J.; Kim, N. Y.; Kim, Y. H.; Jung, Y.; Single-atom catalysts for $\mathrm{CO}_{2}$ electroreduction with significant activity and selectivity improvements. Chem. Sci., 2017, 8, 1090-1096.

2. He, H.; Jagvaral, Y. Electrochemical reduction of $\mathrm{CO}_{2}$ on graphene supported transition metals-towards single atom catalysts. Phys. Chem. Chem. Phys., 2017, 19, 11436-11446. 